\title{
Need for recovery across work careers: the impact of work, health and personal characteristics
}

Citation for published version (APA):

Gommans, F. G., Jansen, N. W. H., Stynen, D., de Grip, A., \& Kant, IJ. (2015). Need for recovery across work careers: the impact of work, health and personal characteristics. International Archives of Occupational and Environmental Health, 88(3), 281-295. https://doi.org/10.1007/s00420-014-0956-3

Document status and date:

Published: 01/01/2015

DOI:

10.1007/s00420-014-0956-3

Document Version:

Publisher's PDF, also known as Version of record

Document license:

Taverne

Please check the document version of this publication:

- A submitted manuscript is the version of the article upon submission and before peer-review. There can be important differences between the submitted version and the official published version of record.

People interested in the research are advised to contact the author for the final version of the publication, or visit the DOI to the publisher's website.

- The final author version and the galley proof are versions of the publication after peer review.

- The final published version features the final layout of the paper including the volume, issue and page numbers.

Link to publication

\footnotetext{
General rights rights.

- You may freely distribute the URL identifying the publication in the public portal. please follow below link for the End User Agreement:

www.umlib.nl/taverne-license

Take down policy

If you believe that this document breaches copyright please contact us at:

repository@maastrichtuniversity.nl

providing details and we will investigate your claim.
}

Copyright and moral rights for the publications made accessible in the public portal are retained by the authors and/or other copyright owners and it is a condition of accessing publications that users recognise and abide by the legal requirements associated with these

- Users may download and print one copy of any publication from the public portal for the purpose of private study or research.

- You may not further distribute the material or use it for any profit-making activity or commercial gain

If the publication is distributed under the terms of Article $25 \mathrm{fa}$ of the Dutch Copyright Act, indicated by the "Taverne" license above, 


\title{
Need for recovery across work careers: the impact of work, health and personal characteristics
}

\author{
F. G. Gommans • N. W. H. Jansen · D. Stynen • \\ A. de Grip • IJ. Kant
}

Received: 19 July 2013 / Accepted: 22 June 2014 / Published online: 3 July 2014

(C) Springer-Verlag Berlin Heidelberg 2014

\begin{abstract}
Purpose Employees experiencing a high need for recovery (NFR) are at risk of long-term adverse effects in both their health and labour participation. So far, the determinants of NFR across age categories remain unknown. The aim of this study is to investigate the determinants of the NFR among employees in three age categories (30-44, 4554 and 55-65 years), for men and women separately.

Methods The study was based on data from the prospective Maastricht Cohort Study. Wave T3 (May 1999) was chosen as article baseline $(n=7,900)$. The followup period of 20 months included five follow-up waves. Cox regression analyses were performed to investigate the determinants, which originated from the work environment, health and lifestyle and personal domain of employees, of NFR across age categories over time.

Results Cross-sectional results demonstrated substantial differences in mean scores and proportion of cases of NFR across age categories. Longitudinal analyses demonstrated risk factors in the multifactorial aetiology of NFR that played a role in all age categories, but also showed several age-specific risk factors, e.g. low decision latitude appeared to be a risk factor only in the oldest age category.
\end{abstract}

Conclusions Although selection effects may have occurred, this study shows that the risk factors for a high

F. G. Gommans $(\varangle) \cdot$ N. W. H. Jansen · D. Stynen · I. Kant Department of Epidemiology, CAPHRI School for Public Health and Primary Care, Faculty of Health, Medicine and Life Sciences, Maastricht University, P.O. Box 616, 6200 MD Maastricht, The Netherlands

e-mail: Fleur.Gommans@maastrichtuniversity.nl

A. de Grip

Research Centre for Education and the Labour Market (ROA),

Maastricht University, Maastricht, The Netherlands
NFR were different among the age categories. To prevent and reduce a high NFR among employees, it is important to develop preventive measures that target age-specific risk factors.

Keywords Need for recovery - Employees · Ageing · Determinants $\cdot$ Epidemiology $\cdot$ Gender

\section{Introduction}

During working days, employees use and deplete mental and physical resources (Hartig and Staats 2003). The need to recuperate from work-induced effects is determined by work demands related to the ability to cope with these demands and the mental and physical capacity of employees (de Vries-Griever 1992). To measure the extent to which work tasks induce a need to recuperate from workinduced efforts (Jansen et al. 2002), the concept of need for recovery (NFR) can be used, reflecting the short-term effects of a working day (van Veldhoven and Meijman 1994; Sluiter et al. 2001). Employees who experience a high NFR are characterised by feelings of overload, irritability, social withdrawal, lack of energy for new effort and reduced performance (van Veldhoven 2008).

With regard to labour participation, elevated levels of NFR can lead to a reduction in working hours (de Raeve et al. 2009). Furthermore, NFR is related to adverse health consequences. A high NFR is a predictor of subjective health complaints (Sluiter et al. 2003), sickness absence (de Croon et al. 2003) and cardiovascular diseases (van Amelsvoort et al. 2003). Adverse health factors may predict subsequent early retirement intentions among older workers (von Bonsdorff et al. 2010). Overall, the NFR levels differ with age: Kiss et al. (2008) found the highest levels of NFR 
among older ( $\geq 45$ years) workers compared to younger ( $<45$ years) workers, and Mohren et al. (2010) observed the highest levels of NFR in the 46-55-year-old category. In both studies, the NFR decreased after the age of 55 years.

As yet, reasons for the differences in the NFR across age groups remain relatively unknown, but may be found in different age-specific determinants of NFR across the lifetime of an individual. For example, Jansen et al. (2003b) found that work-family conflict is a strong risk factor for the onset of a high NFR. In one study, work-family conflict was most prevalent among employees aged 36-45 (Jansen et al. 2004) and this might partially explain elevated levels of NFR in that particular age category. In addition to agespecific determinants, different age-underlying processes might explain why some determinants (e.g. work demands) relate differently to a high NFR across the lifetime. On the one hand, it is generally assumed that mental and physical capacities tend to decrease with age (Ilmarinen 2001; Salthouse 2006), thereby making older workers, compared to younger workers, more prone to developing a high NFR when given equal work demands. On the other hand, lifespan theories such as the Theory of Selective Optimization with Compensation (SOC) of Baltes et al. (1999) suggest that, in the face of capacity constraints, older employees may maintain a high level of job functioning because they rely more heavily on regulatory SOC strategies compared to younger workers. More specifically, older employees are more likely to focus on a reduced number of achievable tasks (i.e. selection) while at the same time committing themselves more strongly to this smaller number of tasks (i.e. optimisation). When the latter strategies are no longer sufficient, older employees might rely more strongly on external aid (i.e. compensation) to maintain their overall job functioning. Currently, insight into the relationship between age-specific determinants from various domains and a high NFR across the lifetime is lacking.

To allocate the NFR and its determinants, the model of Work load and Work capacity of van Dijk et al. (1990) will be used. This model provides a scheme that describes several work-related demands in relation to work capacity and their short- and long-term effects. When employees experience excessive work demands and/or a lack of capacity to manage these demands, this might result in insufficient recovery after work, inducing adverse long-term effects on health and labour participation. As recommended by van Dijk et al. (1990), the model should be considered as a basic scheme, indicating that, for specific applications, elaboration may be appropriate. Therefore, in addition to the 'work environment' domain, two other domains with potential determinants of the NFR were included, comprising the domains 'health and lifestyle' and 'personal characteristics'. The effect of the determinants from all three domains on the NFR of employees will be investigated.
A few examples of factors originating from these three domains that have been associated with a high NFR are high emotional workload (van Veldhoven and Broersen 2003), suffering from a long-term illness (Jansen et al. 2002) and a low educational level (Jansen et al. 2002). Moreover, according to Kiss et al. (2008), the NFR will not be a problem if employees have a sufficient amount of time to recover between periods of work. Factors such as taking care of children living at home or taking care of a chronically ill person might limit the opportunities and time available to recover. However, these abovementioned studies are based on cross-sectional data, which do not allow causal conclusions. Moreover, it remains unknown whether the impact of these determinants varies across an individual's lifetime.

When investigating the impact of these domains on the NFR, the role of gender cannot be ignored: different studies have shown that gender is a proxy for exposure to several potential determinants found in different domains (Kennedy and Koehoorn 2003; Messing et al. 2003). Examples of differences between men and women with regard to exposure to potential determinants of NFR may, amongst others, comprise the exposure to ergonomic demands (Silverstein et al. 1986), the prevalence of diseases, health perception and health reporting (Niedhammer et al. 2000) and the amount of time spent on domestic tasks and taking care of children (Statistics Netherlands 2012b).

The aim of this study was to gain insight into the longitudinal relationships between the different determinants of NFR, in different age categories and for men and women separately. The Netherlands is currently facing demographic challenges-the population is ageing and the longevity is increasing, whereas the potential labour force is shrinking (Statistics Netherlands 2012a). To make sure that as many employees as possible can work until retirement age in a healthy and motivated way, more insight into the concept of NFR is valuable. This insight could be useful in developing measures to prevent employees at risk of (partly) withdrawing from the labour force early and interventions that contribute to a healthy, motivated and wellfunctioning work career across an employee's lifetime.

\section{Methods}

Sampling and procedures

This study is based on data from the Maastricht Cohort Study (MCS). The MCS was set up in May 1998 and included 12,140 participants from 45 different companies. At baseline measurement, all included participants were aged between 18 and 65 (Kant et al. 2003; Mohren et al. 2007). Written informed consent was obtained from all 
participants. The study was conducted in accordance with the ethical standards laid down in the 1964 Declaration of Helsinki and its later amendments.

In the present study, measurement T3 (May 1999) was defined as article baseline. Waves before T3 were considered unsuitable because the number of employees in the oldest age category was too small. The follow-up duration in this study was 20 months and comprises five follow-up waves until January 2001 (De Raeve et al. 2009), which is considered to be sufficient to investigate the impact of determinants on the NFR of employees (de Raeve 2008). At article baseline, $n=11,272$ questionnaires were sent out and $n=9,655$ valid questionnaires were received. The following response rates of the follow-up waves were observed: at T4, T5, T6, T7 and T8, the number of questionnaires sent out was $n=9,654, n=9,654, n=9,200$, $n=8,033$ and $n=8,033$, respectively, and the number of valid questionnaires received was $n=8,956, n=8,692$, $n=8,070, n=7,662$ and $n=7,482$, respectively.

For a description of the study population, cross-sectional data from the article baseline were used. Three age categories were investigated: 30-44 years (young age category), 45-54 years (middle-aged category) and 55-65 years (old age category). In accordance with the definition of the World Health Organization (1993), this study defined older employees as those aged 45 or older. Participants aged younger than 30 years old and participants older than 65 years old were excluded. Participants who were retired or not employed at article baseline (T3) were excluded as well. Participants involved in multiple jobs were excluded. Finally, due to power limitations, women in the age category 55-65 years old were excluded from the study population. In the descriptive analyses, the study population was stratified by gender, resulting in a study population of $n=7,900$ of which 4,338 were 30-44 years old (3,029 men and 1,309 women), 2,938 were $45-54$ years old (2,419 men and 519 women) and 624 were 55-65 years old (all men). To study incident cases only, prevalent cases of NFR at article baseline were excluded for the longitudinal analyses. This resulted in a study population of $n=5,447$ of which 3,059 were 30-44 years old (2,097 men and 962 women), 1,955 were $45-54$ years old (1,597 men and 358 women) and 433 were 55-65 years old (all men).

Measures

\section{Outcome measure: need for recovery}

NFR was measured at article baseline and at all follow-up waves (T4-T8) and was assessed using a subscale from the Dutch Questionnaire on the Experience and Evaluation of Work (Dutch abbreviation: VBBA) (van Veldhoven and Broersen 2003). The scale comprises 11 dichotomous items (yes/no), representing short-term effects of a day at work. This results in a scoring range of $0-11$. Next, the scale was transformed to a scale that included a scoring range of $0-100$, with a higher score indicating a higher NFR. Cronbach's alpha of the scale is 0.78 (Jansen et al. 2002). An example of an item is 'I find it hard to relax at the end of a working day'. In this study, a cut-off point of six on the eleven-item scale was used to define cases with a high (scoring above the cut-off point) and a low-medium (scoring below the cut-off point) NFR. This cut-off point was defined earlier in the study of Broersen et al. (2004).

\section{Work environment determinants}

The (sub)scales and items for all domains were measured at article baseline. For the work environment, several (sub) scales and items were included. With regard to working hours, employees were asked to indicate their working hours per week. The five answer options were recoded into three categories: a full-time job ( $>40$ or $36-40 \mathrm{~h}$ per week), a major part-time job (26-35 h per week) or a minor part-time job (16-25 or $<16 \mathrm{~h}$ per week). Furthermore, one dichotomous item (yes/no) asked whether employees worked overtime regularly and one item measured whether employees were engaged in day work or shift work. To measure the job content, several scales from a validated Dutch version (Houtman 1995) of the Job Content Questionnaire (JCQ) by Karasek (1985) were used. Psychological job demands were measured by the sum of five items, including questions about excessive amounts of work and experiencing conflicting demands. Decision latitude was measured by combining two subscales: skill discretion and decision authority. Also, two scales from the JCQ were included to measure social support: one scale measured co-worker social support and one scale measured supervisor social support. Both scales consisted of four items. All scales from the JCQ had four response options, ranging from 'strongly disagree' to 'strongly agree'. Two dichotomous items (yes/no) from the VBBA were included to gain more insight into conflicts at work. Emotional demands (yes/no) were measured with one item from the VBBA. One dichotomous item from the Dutch questionnaire on Work and Health (Dutch abbreviation: VAG) (Gründemann et al. 1993) was used to question whether participants considered their job to be strenuous (yes/no). Job insecurity was measured with a dichotomous item (yes/no) from the VBBA (van Veldhoven and Meijman 1994).

\section{Health and lifestyle determinants}

To measure the perceived general health status of the participants, one item from the SF-36 Health Survey (Aaronson et al. 1998) was used: 'How would you rate your 
health in general?' In accordance with earlier studies (Dalstra et al. 2002; de Raeve et al. 2007), this measure was dichotomised by grouping the five response scores into 'good general health' and 'poor general health'. Long-term illnesses were measured with the use of one dichotomous (yes/no) item. One self-formulated item on depressed mood was included: 'During the last 2 weeks, did you feel depressed nearly every day? (yes/no)'. Furthermore, one self-formulated item on sleep complaints was included: 'How often did you sleep well during the last 4 months?' This measure was dichotomised by recoding the four response options into 'no chronic sleep complaints' and 'chronic sleep complaints'. Regarding lifestyle factors, two items were included: 'Do you smoke daily? (yes/no)' and 'During leisure time how many times per week are you engaged in physical activity for at least half an hour?' Response options were never or once a week, 2-7 times a week or more than 7 times a week.

\section{Personal determinants}

Demographic items were all measured at article baseline except for educational level, which was measured at study baseline (May 1998) and was categorised as low, medium or high. Furthermore, self-formulated items were included on whether participants took care of children living at home (yes/no), whether they experienced shocking life events in their private life during the last year, for example suffering from a severe illness or going through a divorce (yes/no), and whether they took care of a chronically ill person at home (yes, partner/yes, child(ren)/yes, family/no). The latter measure was dichotomised by grouping response scores 'yes, partner' 'yes, child(ren)' and 'yes, family' into 'yes'. Items were included indicating whether participants lived alone (yes/no) and whether participants were satisfied with their financial circumstances (yes/no). A self-formulated item (yes/no) was included to measure work-family conflict (Mohren et al. 2007).

\section{Statistical analysis}

In both descriptive and longitudinal analyses, the results were stratified by gender. To test for differences among the three age categories in the prevalence of characteristics of all three domains and the proportion of NFR cases, chisquared tests were conducted. As the distribution of NFR was skewed to the right, Poisson regression analysis was conducted to test for differences in mean levels among age categories.

Before investigating the determinants of NFR among the age categories, a multi-group confirmatory factor analysis (CFA) was executed to determine whether the NFR scale showed measurement invariance among the age categories.
All items were included in the CFA as indicators to test the latent factor NFR across age categories. The comparative fit index (CFI), the root mean square error of approximation (RMSEA), the weighted root mean square residual (WRMR) and the chi-squared test were investigated to determine the overall model fit. To compare the fit of nested models, we relied, in line with Wu et al. (2007), on the difference in CFI $(\triangle \mathrm{CFI})$ since the latter is unbiased for sample size compared to the difference in $\chi^{2}\left(\Delta \chi^{2}\right)$. A cutoff point of $\Delta \mathrm{CFI} \leq 0.01$ was considered to be adequate when determining the equivalence of nested models (Wu et al. 2007). In the longitudinal analyses, the influence of the domains on NFR was determined for different age categories using Cox regression. The time to first 'NFR caseness' was modelled at T4, T5, T6, T7 or T8. Hazard ratios (HRs) and $95 \%$ confidence intervals (CIs) were reported. In the crude model, the HRs of NFR were adjusted for educational level. Based on conceptual reasons, the number of working hours per week, shift work, living situation and long-term illnesses were included as correction variables in the adjusted model. In earlier studies, these variables were associated with different levels of NFR (Jansen et al. 2002, 2003a; Van Veldhoven and Broersen 2003; Mohren et al. 2010). The proportional hazard assumption was investigated in both the crude and adjusted models. Overall, the proportional hazard assumption was met, although in a small minority of the models, the assumption was violated. Among men, this concerned only decision latitude and educational level in the youngest age category and the experience of shocking life events in the middle-aged category. Among women, this concerned only decision latitude in the middle-aged category. In all analyses, a $p$ value of $<0.05$ was considered statistically significant. SPSS 20.0 and Mplus 6.0 were used to analyse the data.

\section{Results}

Measurement invariance of the need for recovery scale

The results of the multi-group CFA are presented in Table 1 and show that the hypothesised one-factor model (M0) had an insufficient fit across age categories. Inspection of this model showed that this insufficient fit was caused by two pairs of indicators that correlated highly, namely item 2 with item 3 and item 7 with item 9. The measurement errors of these pairs of items were subsequently allowed to correlate across all age categories in model M1, to appropriately account for this. This resulted in a good model fit suggesting configural measurement invariance across the age categories. Next, an additional CFA was performed to compare the fit of the latter model in which factor loadings were estimated freely across age categories with the fit 
Table 1 Multi-group confirmatory factor analysis of the need for recovery scale

\begin{tabular}{lrllllllr}
\hline One-factor model & \multicolumn{1}{l}{$\chi^{2}$} & $d f$ & RMSEA & CFI & WRMR & Versus & $\Delta \chi^{2}(\Delta d f)$ & $\Delta$ CFI \\
\hline M0 & $2,360.734^{*}$ & 132 & 0.096 & 0.829 & 6.074 & & & \\
M1 correlated uniquenesses (E2, E3 and E7, E9) & $781.645^{*}$ & 130 & 0.052 & 0.950 & 3.428 & M0 vs. M1 & $1,094.112(2)^{*}$ & 0.121 \\
M2 plus factor loadings equal & $782.829^{*}$ & 150 & 0.048 & 0.951 & 3.622 & M1 vs. M2 & $57.442(20)^{*}$ & 0.001 \\
\hline
\end{tabular}

$* p<0.05$

of an alternative model (M2) in which the factor loadings were constrained. Based on the $\triangle \mathrm{CFI} \leq 0.01$ decision rule, it can be concluded that no substantial differences were observed when comparing models M1 and M2. Model M2 is preferred as this is the more parsimonious model. Having established configural invariance as well as invariance of factor loadings, relationships between determinants of NFR across age categories can be meaningfully compared in further analyses.

\section{Descriptives study population}

In Table 2, the article baseline cross-sectional results of the prevalence of characteristics from all three domains are presented. In the oldest age category, results are only presented for men, as the number of women in that age category was considered to be insufficient for further analyses.

In the domain of work environment, differences between the three age categories were observed. For example, the highest percentage of employees performing shift work was found in the youngest age category and the highest percentage of employees performing emotionally demanding work was found among the middle-aged category. Furthermore, within the stratum of gender, differences were observed. For example, within men, the highest percentages of performing overtime work and physically demanding work were found in the youngest age category. With regard to health and lifestyle factors, differences between the three age categories were also observed: the highest percentage of chronic sleep complaints was found in the middle-aged category. Within the stratum of women, the highest percentage of the presence of a long-term illness was found in the middle-aged category. Differences among age categories were also found in the domain of personal characteristics. For example, the highest percentage of employees taking care of children living at home was found in the youngest age category. Among the stratum of men, the highest percentage experiencing a work-family conflict was found in the youngest age category. When investigating the NFR, the highest percentage of cases was found in the middleaged category among both men and women. Also, the highest mean scores of NFR were found in this age category among both men and women.
Determinants of need for recovery across age categories overtime

Results of the Cox regression analyses showed that several variables from all three domains constitute risk factors for an elevated NFR. For all three domains, both the risk factors that are statistically significant in all age categories and statistically significant age-specific risk factors will be presented. Tables 3, 4 and 5 include both crude and adjusted models; only adjusted models will be described.

As shown in Table 3, both subjective and objective work characteristics of the work environment are associated with and constitute several risk factors for a high NFR. Work determinants that were statistically significantly related to a high NFR in all age categories were the performance of physically demanding work and having a conflict with the supervisor. An example of a subjective work characteristic that proved to be a risk factor of NFR in the youngest and middle age category was high psychological job demands, whereas low decision latitude was only a risk factor among the oldest age category. Low social support from the supervisor or low support from co-workers was a risk factor for the youngest and middle age category, but was not a risk factor of a high NFR among the oldest category. When comparing differences across age categories within the stratum of gender, some risk factors were only found in certain age categories. More specifically, in men the objective characteristic overtime work was found to be a risk factor only in the youngest age category.

The domain of health and lifestyle constitutes characteristics related to mental and/or physical health and lifestyle characteristics. Among these characteristics, both risk factors and protective factors for a high NFR were found, as shown in Table 4. Having a poor general health status was the only risk factor for all age categories found in this domain. Suffering from chronic sleep complaints was a risk factor for elevated NFR only among the youngest and middle age categories, and suffering from depressed mood was a risk factor only among the youngest and oldest age categories. When further comparing differences across age categories within the stratum of gender, among men the presence of a long-term illness was statistically significantly related to a high NFR in all age categories, whereas in women this was only found to be a risk factor 
Table 2 Description of the work environment, health and lifestyle determinants, personal characteristics and need for recovery of the study population at baseline measurement (May, 1999) according to age category and gender

\begin{tabular}{|c|c|c|c|c|c|c|c|}
\hline Age category & $30-44$ years & & $45-54$ years & & $55-65$ years & $\chi^{2} p$ & \\
\hline Gender & Male $(n=3,029)$ & Female $(n=1,309)$ & Male $(n=2,419)$ & Female $(n=519)$ & Male $(n=624)$ & Men & Women \\
\hline
\end{tabular}

Work environment

Number of working hours per week $(\%)$

$\begin{array}{lrr}\geq 36 & 85.0 & 29.9 \\ 26-35 & 14.3 & 22.0 \\ \leq 25 & 0.7 & 48.0\end{array}$

$29.9 \quad 89.7$

48.0

Shift work $(\%)$

$\begin{array}{lll}\text { Yes } & 34.4 & 22.3\end{array}$

$\begin{array}{lll}\text { No } & 65.6 & 77.7\end{array}$

Overtime work (\%)

Yes $\quad 50.0$

No $\quad 50.0$

37.4

62.6

Psychological job demands (\%)

$\begin{array}{lll}\text { Low } & 32.7 & 39.5 \\ \text { Medium } & 33.4 & 34.4 \\ \text { High } & 33.9 & 26.1\end{array}$

High $\quad 33.9$

$$
26.1
$$

Decision latitude $(\%)$

$\begin{array}{lll}\text { Low } & 30.0 & 41.5 \\ \text { Medium } & 36.4 & 35.1\end{array}$

$\begin{array}{lll}\text { High } & 33.6 & 23.4\end{array}$

Perceived job insecurity (\%)

$\begin{array}{lrr}\text { Yes } & 7.1 & 9.9 \\ \text { No } & 92.9 & 90 .\end{array}$

Emotional demanding work (\%)

$\begin{array}{lll}\text { Yes } & 22.3 & 40.2\end{array}$

No $\quad 77.7$

Physically demanding work (\%)

$\begin{array}{lll}\text { Yes } & 22.7 & 24.8 \\ & 77.3 & 75.2\end{array}$

$\begin{array}{lll}\text { No } & 77.3 & 75.2\end{array}$

Co-worker social support (\%)

$\begin{array}{lll}\text { Low } & 30.4 & 24.2 \\ \text { High } & 69.6 & 75.8\end{array}$

Supervisor social support (\%)

$\begin{array}{lll}\text { Low } & 43.8 & 39.6\end{array}$

$\begin{array}{lll}\text { High } & 56.2 & 60.4\end{array}$

Conflict with co-workers (\%)

$\begin{array}{lrr}\text { Yes } & 7.2 & 4.2 \\ \text { No } & 92.8 & 95.8\end{array}$

Conflict with supervisor (\%)

$\begin{array}{lrr}\text { Yes } & 8.8 & 4.5 \\ \text { No } & 91.2 & 95.5\end{array}$

Health and lifestyle

Perceived general health status (\%)

\begin{tabular}{|c|c|c|c|c|c|c|c|}
\hline Good & 87.0 & 83.1 & 82.7 & 81.8 & 83.2 & $<0.0001$ & 0.493 \\
\hline Poor & 13.0 & 16.9 & 17.3 & 18.2 & 16.8 & & \\
\hline \multicolumn{8}{|c|}{ Presence of a long-term illness (\%) } \\
\hline Yes & 15.4 & 20.3 & 25.8 & 28.3 & 28.9 & $<0.0001$ & $<0.0001$ \\
\hline No & 84.6 & 79.7 & 74.2 & 71.7 & 71.7 & & \\
\hline
\end{tabular}


Table 2 continued

\begin{tabular}{|c|c|c|c|c|c|c|c|}
\hline \multirow{2}{*}{$\begin{array}{l}\text { Age category } \\
\text { Gender }\end{array}$} & \multicolumn{2}{|l|}{ 30-44 years } & \multicolumn{2}{|l|}{$45-54$ years } & \multirow{2}{*}{$\begin{array}{l}55-65 \text { years } \\
\text { Male }(n=624)\end{array}$} & \multicolumn{2}{|l|}{$\chi^{2} p$ value } \\
\hline & Male $(n=3,029)$ & Female $(n=1,309)$ & Male $(n=2,419)$ & Female $(n=519)$ & & Men & Women \\
\hline \multicolumn{8}{|c|}{ Depressed mood (\%) } \\
\hline Yes & 6.7 & 7.5 & 8.3 & 9.9 & 6.5 & 0.061 & 0.087 \\
\hline No & 93.3 & 92.5 & 91.7 & 90.1 & 93.5 & & \\
\hline \multicolumn{8}{|c|}{ Chronic sleep complaints (\%) } \\
\hline Yes & 14.9 & 14.1 & 19.1 & 23.4 & 18.6 & $<0.0001$ & $<0.0001$ \\
\hline No & 85.1 & 85.9 & 80.9 & 76.6 & 81.4 & & \\
\hline \multicolumn{8}{|c|}{ Daily smoker (\%) } \\
\hline Yes & 23.4 & 26.4 & 26.4 & 30.8 & 24.7 & 0.040 & 0.063 \\
\hline No & 76.6 & 73.6 & 73.6 & 69.2 & 75.3 & & \\
\hline \multicolumn{8}{|c|}{ Physical activity per week (\%) } \\
\hline 0-1 Times & 33.3 & 33.4 & 31.0 & 30.6 & 30.9 & & \\
\hline 2-7 Times & 59.8 & 62.2 & 62.4 & 62.5 & 63.8 & 0.159 & 0.070 \\
\hline >7 Times & 6.9 & 4.4 & 6.6 & 6.9 & 5.3 & & \\
\hline \multicolumn{8}{|c|}{ Personal characteristics } \\
\hline \multicolumn{8}{|c|}{ Educational level (\%) } \\
\hline Low & 18.8 & 8.8 & 24.0 & 19.8 & 24.1 & & \\
\hline Medium & 40.9 & 58.1 & 41.0 & 51.0 & 40.8 & $<0.0001$ & $<0.0001$ \\
\hline High & 40.3 & 33.1 & 35.0 & 29.2 & 35.1 & & \\
\hline \multicolumn{8}{|c|}{ Living alone (\%) } \\
\hline Yes & 10.9 & 9.4 & 6.5 & 12.8 & 4.2 & $<0.0001$ & 0.030 \\
\hline No & 89.1 & 90.6 & 93.5 & 87.2 & 95.8 & & \\
\hline \multicolumn{8}{|c|}{ Taking care of children living at home (\%) } \\
\hline Yes & 64.9 & 60.7 & 56.5 & 43.1 & 22.5 & $<0.0001$ & $<0.0001$ \\
\hline No & 35.1 & 39.3 & 43.5 & 56.9 & 77.5 & & \\
\hline \multicolumn{8}{|c|}{ Taking care of a chronically ill person at home $(\%)$} \\
\hline Yes & 12.2 & 11.7 & 15.2 & 15.7 & 16.8 & $<0.0001$ & $<0.019$ \\
\hline No & 87.8 & 88.3 & 84.8 & 84.3 & 83.2 & & \\
\hline \multicolumn{8}{|c|}{ Life events in private life last year (\%) } \\
\hline Yes & 28.1 & 32.5 & 34.0 & 39.1 & 31.2 & $<0.0001$ & 0.008 \\
\hline No & 71.9 & 67.5 & 66.0 & 60.9 & 68.8 & & \\
\hline \multicolumn{8}{|c|}{ Satisfaction with financial circumstances (\%) } \\
\hline Yes & 81.5 & 89.0 & 85.2 & 90.5 & 89.1 & $<0.0001$ & 0.359 \\
\hline No & 18.5 & 11.0 & 14.8 & 9.5 & 10.9 & & \\
\hline \multicolumn{8}{|c|}{ Work-family conflict (\%) } \\
\hline Yes & 11.2 & 7.7 & 8.3 & 6.1 & 6.0 & $<0.0001$ & 0.230 \\
\hline No & 88.8 & 92.3 & 91.7 & 93.9 & 94.0 & & \\
\hline \multicolumn{8}{|c|}{ Need for recovery } \\
\hline Case & 30.4 & 26.1 & 33.7 & 30.6 & 31.7 & 0.029 & 0.049 \\
\hline Non-case & 69.6 & 73.9 & 66.3 & 69.4 & 68.3 & & \\
\hline \multicolumn{8}{|c|}{ Need for recovery } \\
\hline Mean & & & & & & $<0.0001^{\mathrm{a}}$ & $<0.0001^{\mathrm{a}}$ \\
\hline Score & 37.69 & 34.80 & 40.22 & 37.29 & 36.35 & $<0.0001^{\mathrm{b}}$ & \\
\hline & & & & & & $<0.0001^{\mathrm{c}}$ & \\
\hline
\end{tabular}

${ }^{a} p$ value for comparing age categories 30-44 and 45-54

b $p$ value for comparing age categories $30-44$ and 55-65

${ }^{c} p$ value for comparing age categories 45-54 and 55-65 


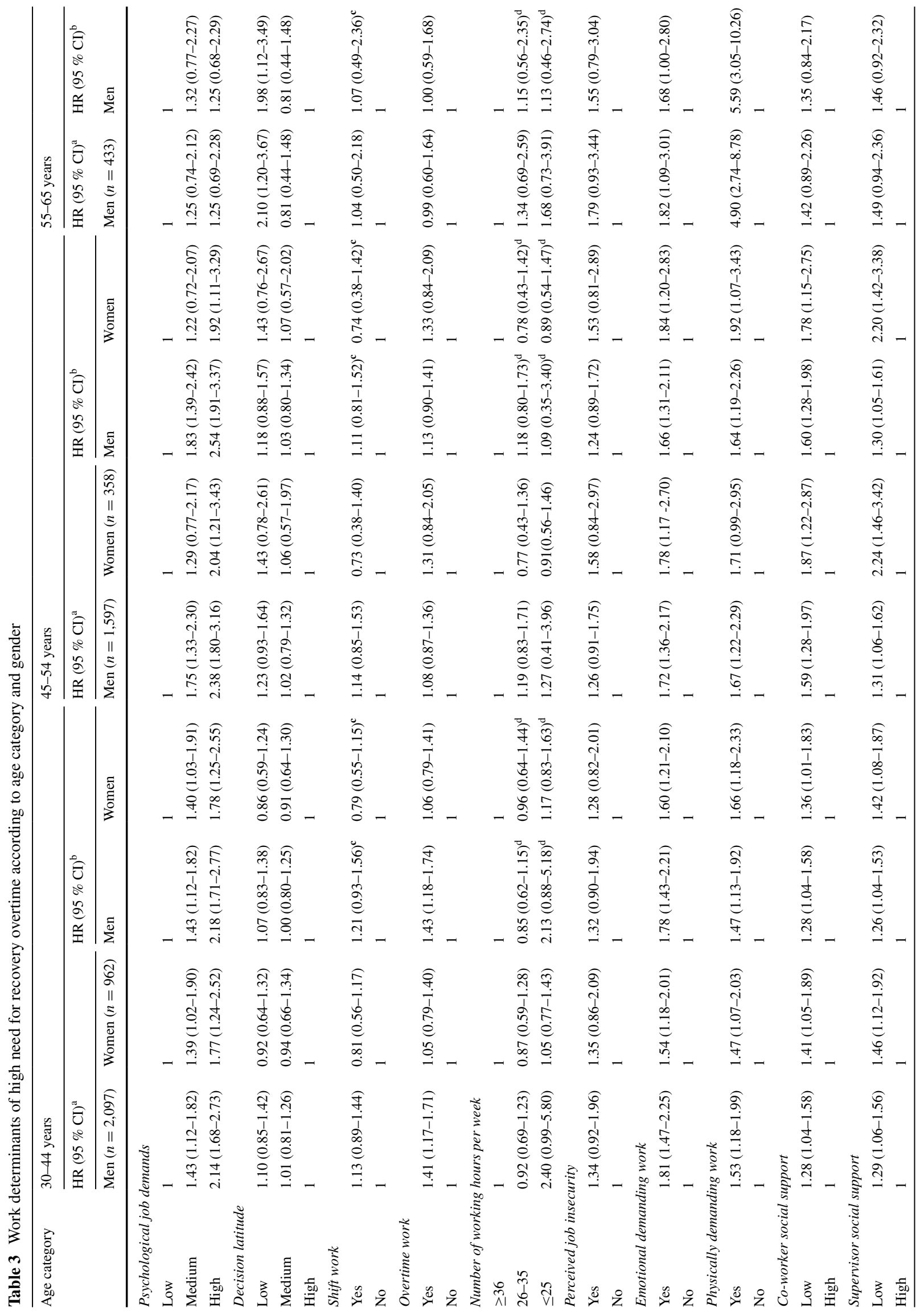




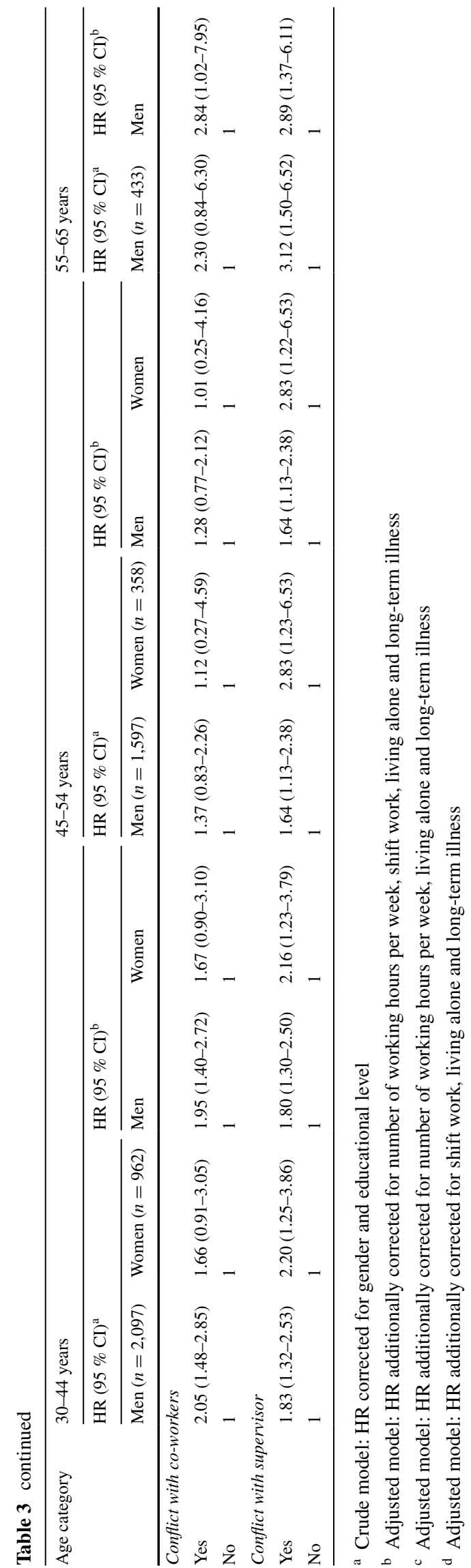

in the youngest age category. The performance of physical activity over seven times a week was found to be protective against a high NFR among men in the youngest and middle age category.

In the domain of personal characteristics, both demographic factors and characteristics of the private situation were investigated. As shown in Table 5, no personal characteristics were observed that were statistically significantly associated with the NFR in all three age categories in both men and women. However, being unsatisfied with financial circumstances was a risk factor for a high NFR among men in all three age categories and for women only in the youngest age category. The experience of a life event in their private life within the last year was found to be a risk factor for a high NFR in the oldest age category and among women in the youngest age category. When investigating the characteristics within the stratum of gender, several risk factors were found within the private situation. Workfamily conflict was only found to be a risk factor for a high NFR among men in the youngest age category and taking care of a chronically ill person at home was only a risk factor among men in the middle-aged category.

\section{Discussion}

The aim of this study was to investigate the NFR and its determinants across three age categories and for men and women separately.

The cross-sectional analyses showed substantial age differences in the mean scores of NFR. In line with earlier studies (Kiss et al. 2008; Mohren et al. 2010), the highest mean scores were observed among older employees when compared to younger employees, whereas a substantial decrease of NFR was observed among employees aged 55 or older.

With regard to gender differences, men reported higher NFR mean scores when compared to women in the same age category. However, other studies observed higher NFR scores among women compared to men (Kiss et al. 2008; Verdonk et al. 2010). Explanations for these gender differences might be that these studies included different samples and settings. For example, the study of Kiss et al. (2008) only included employees working in the public sector, and the study of Verdonk et al. (2010) observed the highest NFR mean scores among highly educated women, in particular those aged 50-64 years. In our study population, these women were less represented, as the largest proportion of women in our study had a low-medium educational level, and women aged 55 and older were excluded from the study population due to power limitations.

The longitudinal results revealed factors that proved to be statistically significantly related to a high NFR in all 


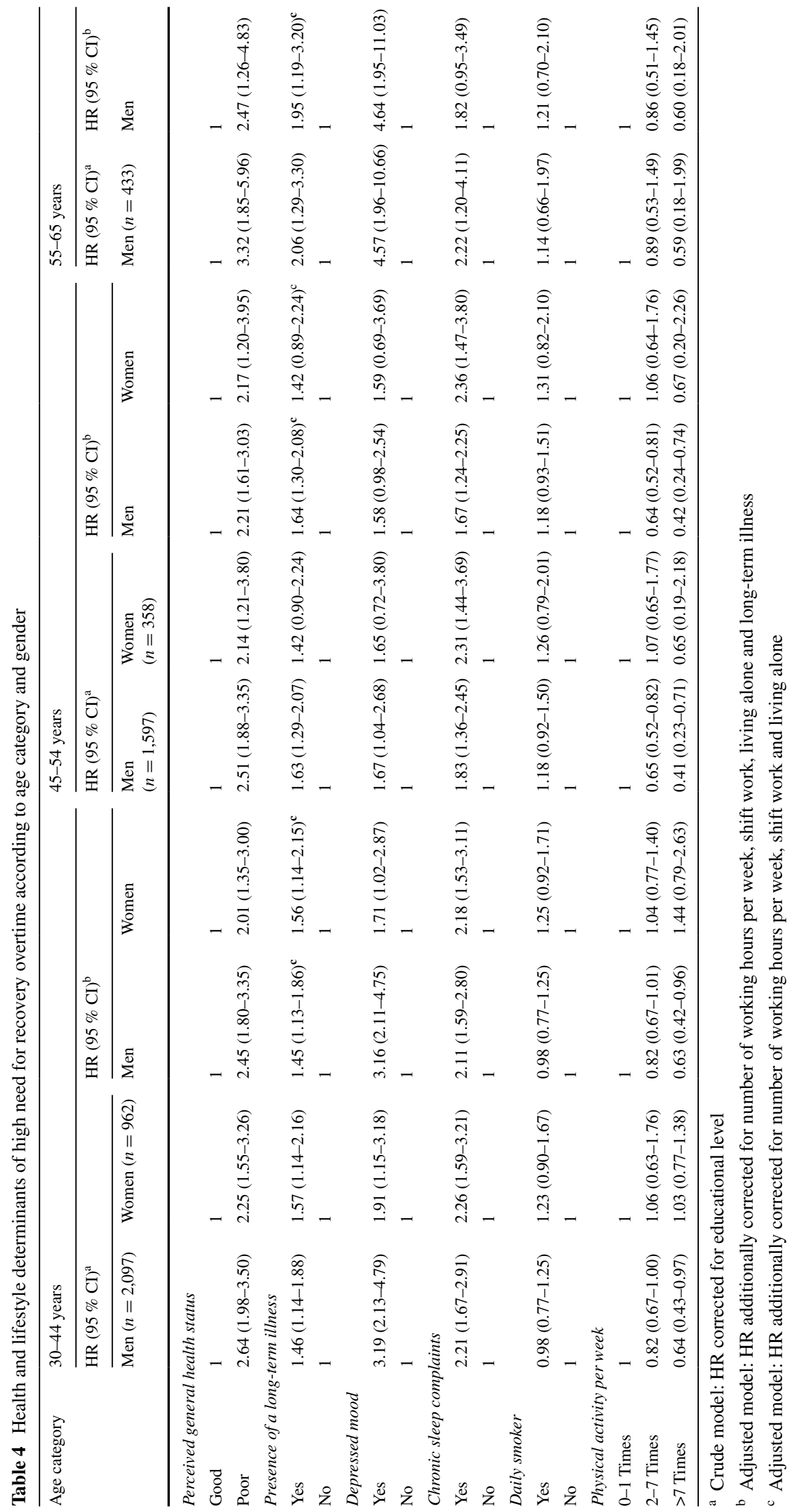




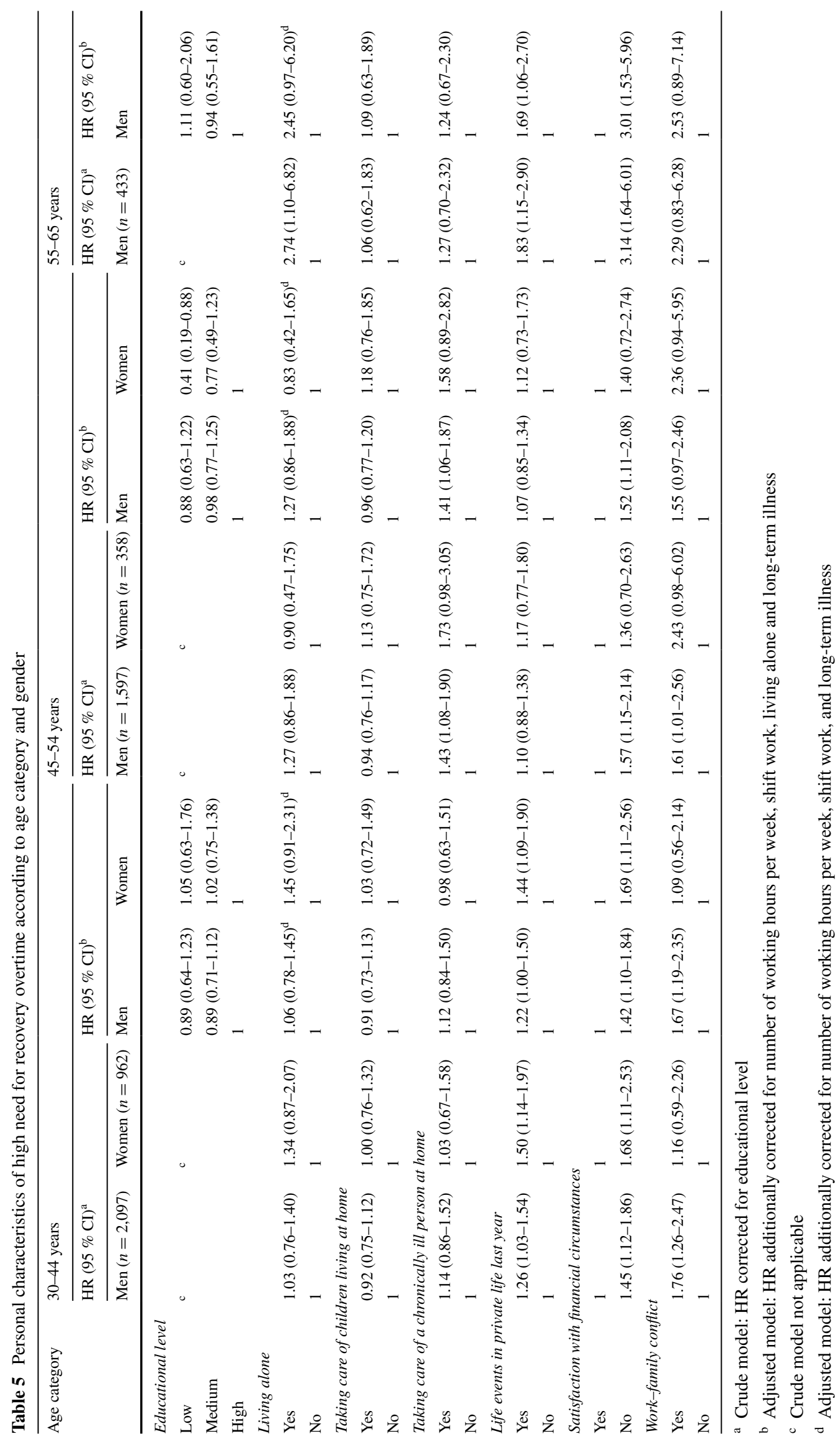


age categories, as well as some risk factors that proved to be more age-specific. For example, high psychological job demands, which is a work-related risk factor for elevated NFR, was only found among the youngest and middle age category, but was no longer found among the oldest employees. A possible explanation for the absence of this risk factor in the oldest age category might be that the oldest employees rely heavily on SOC strategies to cope with these demands (Baltes et al. 1999). Another possibility could be that the psychological job demands of the oldest employees have been adjusted to their age, as workload reduction is a widely implemented measure by employers as a part of the policy to spare older employees (Remery et al. 2003). However, low decision latitude was only found to be a risk factor for an elevated NFR among the oldest age category. A possible explanation could be that, in particular, older employees value a work environment that involves more freedom and authority (Wright and Hamilton 1978).

Although low social support from co-workers and low social support from the supervisor were found to be risk factors in the youngest and middle age categories, this could not be confirmed in the oldest age category. The only objective characteristic of the work environment was the performance of overtime work, which was found to be a risk factor for a high NFR among men in the youngest age category, but not among women in this age category. A possible explanation could be that, on average, the amount of overtime hours per week is higher among men compared to women (Statistics Netherlands 2011), which may result in less opportunities and time to recover. Employees who were not able to withstand the effects that accompany overtime work may have already adjusted their work situation (de Raeve 2008), which might explain why overtime work is not a risk factor among the middle and oldest age categories. The number of working hours per week and shift work were found to be associated with a high NFR in the study of Jansen et al. (2003a) but were not found to be risk factors in the current study, even though both studies are based on the same cohort. An explanation for these apparently contradictory results could be found in the fact that the study of Jansen et al. (2003a) is a cross-sectional study, whereas the current study investigates longitudinal relationships. If the NFR scores were already high at article baseline and are sustained overtime, these relationships might no longer be observed in a longitudinal design, where only incident cases are studied, because the effect was already present. Another explanation for the absence of these risk factors in the longitudinal results could be that employees experiencing a high NFR have already adjusted their work and private situation, which might result in a reduced NFR.

As the risk factors in the work environment differ across the lifespan of individuals, the integration of the concept of age could be a factor of refinement within the Work load and Work capacity model of van Dijk et al. (1990). This would indicate that the interaction between work demands, work capacity and the short- and long-term health effects may vary over a lifetime. Another refinement of the Work load and Work capacity model of van Dijk et al. (1990) could be to further integrate gender as a factor in the model, as risk factors differ between men and women.

In the health and lifestyle domain, several risk factors for an elevated NFR were found. For example, depressed mood was found to be a risk factor in the youngest and oldest age categories. An explanation could be that depressive complaints may present somewhat differently over an individual's lifetime (Fiske et al. 2009), possibly resulting in different types of help-seeking behaviour and coping responses, which might be associated with the NFR. Although sleep complaints were associated with a high NFR in the youngest and middle age categories, this could not be confirmed in the oldest age category.

Regarding personal characteristics, few statistically significant risk factors for a high NFR were observed among the age categories. However, some demographic factors and characteristics of the private situation were found to be risk factors for a high NFR when considering the stratum of gender. For example, living in a household where someone is chronically ill was found to be a risk factor among men in the middle-aged category but not among women in the same category. Not only do men and women often occupy different roles in the private situation (Statistics Netherlands 2012b) but also a possible explanation for this finding could be that men and women perceive these roles differently. Furthermore, it could be that women who experience a work-family conflict may already have adjusted their job, for example by reducing the number of working hours per week (Jansen et al. 2010).

\section{Strengths and limitations}

Several strengths and limitations should be considered. A major strength of this study was that exposure and outcome measures were assessed at separate moments during the follow-up, and therefore, it was possible to investigate the influence of these variables on NFR overtime. The followup duration was considered to be sufficient and included a high number of waves assessing NFR. To investigate true causal relationships, a suggestion for further research is to also assess changes in exposure and outcome overtime. This study included a broad range of variables that were investigated among three different age categories, resulting in several risk factors originating from different domains. Based on the multi-group CFA, it can be concluded that the NFR scale is an adequate measure to investigate the shortterm effects of a working day and is an instrument that can 
provide meaningful comparisons across age categories with regard to relationships between determinants of NFR. Overall, it can be assumed that the external validity of the MCS is quite high (Mohren et al. 2007): the study population consisted of a large, heterogeneous sample of employees with regard to gender, educational level and type of job with a slight over-representation of employees working in industrial companies. As several studies have concluded that men and women differ with regard to exposure in work environment, health and personal characteristics, the stratification of gender is well justified.

Different selection processes may have occurred in this study. To gain insight into the presence of selection bias, a non-response analysis was conducted at baseline T0 (May 1998), which indicated that respondents reported more fatigue complaints compared to non-respondents. This probably resulted in a small overestimation of the prevalence of health outcomes at baseline (Mohren et al. 2007), possibly also with respect to the prevalence of a high NFR. To determine whether selective drop-out may have occurred in the longitudinal analyses, the NFR mean scores reported at $\mathrm{T} 3$ by employees who completed the follow-up until January 2001 were compared to those of employees who dropped out at some point during the follow-up period. Employees who dropped out scored on average 4.73 points higher on the NFR scale compared to employees who completed the follow-up. This finding may be an indication for selective drop-out, implying an underestimation of the mean NFR scores over time.

Employees who suffered from a high NFR might already have changed jobs, adjusted their work situation or left the labour force early: this so-called healthy worker effect results in a selected population of employees that are likely to be healthier and successful at coping with work stressors. The results indicated that the healthy worker effect may also have occurred in this study: the highest mean scores and proportion of cases of NFR were not found among the oldest age category in the cross-sectional analyses, and the results show that employees in the oldest age category may have adjusted their work situation-indications for this are shown in Table 2. Employees in this age category, for example, less often perform shift work, overtime work or physically demanding work compared to employees in the youngest and middle age categories. Therefore, the oldest age category might be considered a selected group, including healthy employees and/or employees who have adjusted their work situation.

The results of this study indicated that some risk factors of NFR may apply for all three age categories, although the association sometimes just failed to reach statistical significance in one of the groups (e.g. emotionally demanding work in the oldest age category). This might indicate that power limitations may be present, and hence, it cannot be ruled out that high emotional demands actually constitute a risk factor of NFR in all three age categories. The opposite was also observed, however, since the results also clearly demonstrated risk factors that were statistically significantly associated with NFR only within a specific age category, consisting of the group with a smaller number of employees (e.g. low decision latitude in the oldest age category). These findings confirm that age-specific risk factors do exist across the lifetime. Due to a small number of female employees in the oldest age category, the oldest age category in this study consisted only of men, and therefore, findings in the oldest age category are only applicable for men and cannot be readily generalised to women.

The results in this study were corrected for several confounders. Confounders were derived from all three domains, and selection was based on theoretical findings. Still, it remains unknown whether the selection of confounders covered all relevant confounders, and therefore, residual confounding cannot be ruled out completely.

In this study, older workers were defined in line with the widespread definition of the World Health Organization, but the definition of the 'older worker' of course remains arbitrary. In the literature, different cut-off points are used to define older workers and Sterns and Alexander (1987) suggested that chronological age is not sufficient to operationalise the factor age in the work setting. Perceived relative age is an example of another possibility to approach the concept of age more comprehensively (Kooij et al. 2008). In our study, however, we were able to further differentiate the group of older employees into two categories (45-54 years and 55-65 years) with sufficient power due to the large study population, at least for men. This approach yielded insight into different risk factors during the process of ageing at work. This valuable finding implies that future studies should also differentiate the group of older employees into more specific age categories.

\section{Conclusion and implications}

This study demonstrated substantial differences in mean scores and proportion of cases of NFR among the three age categories. Although some risk factors of NFR applied for all age categories, the longitudinal analyses also showed that, in the multifactorial aetiology of a high NFR, some risk factors may be more age specific, or sometimes gender specific. Results showed that a downshift is visible among the oldest age category: the oldest employees in our study may represent the healthy workers and/or those who have adjusted their work situation. Also, a group of employees might already have left the labour force before reaching this age category. These findings are in line with current trends on the Dutch labour market, where, in 2011, $67 \%$ of those 
aged 55-60 years and only $35 \%$ of those aged $60-65$ years were employed. Also, a reduction in the number of working hours per week is visible among older employees (Statistics Netherlands 2013). As the heterogeneity of job types in this study was large, it remains unknown whether the risk factors are similar for employees in different job types. A suggestion for further research is to investigate strata of job types or specific subsamples of employees with similar jobs. This might contribute to the establishment of effective job-type-specific preventive measures.

An elevated NFR among employees is itself undesirable and has furthermore been shown to be a precursor of adverse health and labour effects (van Amelsvoort et al. 2003; de Croon et al. 2003; Sluiter et al. 2003). Therefore, preventive measures aimed at reducing risk factors could be beneficial. This study adds that it is important that preventive measures are aimed at specific age categories and target age-specific risk factors, as these differ over the course of a lifetime. An example of such a preventive measure could be an age-conscious personnel policy, since this type of policy aims to keep employees vital, motivated and sustainable during their working life while taking into account different risk factors over their lifetimes. More specifically, the finding that, for instance, low decision latitude is a risk factor for older workers may suggest that organisations may need to invest more in their continuous development (e.g. by providing job enrichment or training). In future studies, a further refinement of age categories and the concept of age should be investigated in order to gain more insight into the course of risk factors during employees' lifetimes.

Acknowledgments The authors thank Jos Slangen for his support in the data management. This study was financially supported by Instituut Gak, Grant no. 2011-089 WR and by School CAPHRI (School for Public Health and Primary Care), Maastricht, the Netherlands.

Conflict of interest The authors declare that they have no conflict of interest.

\section{References}

Aaronson NK, Muller M, Cohen PD, Essink Bot ML, Fekkes M, Sanderman R, Sprangers IMA, te Velde A, Verrips E (1998) Translation, validation, and norming of the Dutch language version of the SF-36 Health Survey in community and chronic disease populations. J Clin Epidemiol 51:1055-1068

Baltes PB, Staudinger UM, Linderberger U (1999) Lifespan psychology: theory and application to intellectual functioning. Annu Rev Psychol 50:471-507

Broersen JPJ, Fortuin RJ, Dijkstra M, van Veldhoven M, Prins J (2004) Monitor Arboconvenanten: kengetallen en grenswaarden [Monitor working conditions agreements: indicators and cutoffs]. Tijdschrift voor Bedrijfs- en Verzekeringsgeneeskunde 12:100-104
Dalstra JAA, Kunst AE, Geurts JJM, Frenken FJM, Mackenbach JP (2002) Trends in socioeconomic health inequalities in the Netherlands, 1981-1999. J Epidemiol Commun Health 56:927-934

De Croon EM, Sluiter JK, Frings-Dresen MH (2003) Need for recovery after work predicts sickness absence: a 2-year prospective cohort study in truck drivers. J Psychosom Res 55:331-339

De Raeve L (2008) Changes in psychosocial work environment and health: a mutual relationship. Dissertation, University of Maastricht

De Raeve L, Jansen NWH, Kant IJ (2007) Health effects of transitions in work schedule, workhours and overtime in a prospective cohort study. Scand J Work Environ Health 33:105-113

De Raeve L, Kant IJ, Jansen NWH, Vasse RM, van den Brandt PA (2009) Changes in mental health as a predictor of changes in working time arrangements and occupational mobility: results from a prospective cohort study. J Psychosom Res 66:137-145

De Vries-Griever AHG (1992) Evenwicht tussen werkdruk en herstel bij afwijkende werktijden. Uitgangspunten voor dienstroosterplanning [Balancing work load and recovery in deviating working hours. Basic principles of rota planning]. Nationaal Ziekenhuisinstituut, Groningen/Utrecht

Fiske A, Wetherell JL, Gatz M (2009) Depression in older adults. Annu Rev Clin Psychol 5:363-389

Gründemann RWM, Smulders PWG, de Winter CR (1993) Handleiding Vragenlijst Arbeid en Gezondheid [Manual, Questionnaire on work and health]. Swets and Zeitlinger, Lisse

Hartig T, Staats H (2003) Guest editors' introduction: restorative Environments. J Environ Psychol 23:103-107

Houtman I (1995) Reliability and validity of the Dutch version of the Karasek Job content questionnaire. NIOSH/APA conference on stress, work, and health, Washington, DC

Ilmarinen JE (2001) Aging workers. Occup Environ Med 58:546-552

Jansen NWH, Kant IJ, van den Brandt PA (2002) Need for recovery in the working population: description and associations with fatigue and psychological distress. Int J Behav Med 9:322-340

Jansen NWH, Kant IJ, van Amelsvoort LGPM, Nijhuis FJN, van den Brandt PA (2003a) Need for recovery from work: evaluating short-term effects of working hours, patterns and schedules. Ergonomics 46:664-680

Jansen NWH, Kant IJ, Kristensen TS, Nijhuis FJN (2003b) Antecedents and consequences of work-family conflict: a prospective cohort study. J Occup Environ Med 45:479-491

Jansen NWH, Kant IJ, Nijhuis FJN, Swaen GMH, Kristensen TS (2004) Impact of worktime arrangements on work-home interference among Dutch employees. Scand J Work Environ Health 30:139-148

Jansen NWH, Mohren DCL, van Amelsvoort LGPM, Janssen N, Kant IJ (2010) Changes in working time arrangements over time as a consequence of work-family conflict. Chronobiol Int 27:1045-1061

Kant IJ, Bültmann U, Schröer CAP, Beurskens AJHM, van Amelsvoort LPGM, Swaen GMH (2003) An epidemiological approach to study fatigue in the working population: the Maastricht Cohort Study. Occup Environ Med 60:i32-i39

Karasek RA (1985) The job content questionnaire and user's guide (version 1.1). Department of Industrial and Systems Engineering, University of Southern California, Los Angeles

Kennedy SM, Koehoorn M (2003) Exposure assessment in epidemiology: does gender matter? Am J Ind Med 44:576-583

Kiss P, de Meester M, Braeckman L (2008) Differences between younger and older workers in the need for recovery after work. Int Arch Occup Environ Health 81:311-320

Kooij D, de Lange A, Jansen P, Dikkers J (2008) Older workers' motivation to continue to work: five meanings of age. J Manag Psychol 23:364-394

Messing K, Punnett L, Bond M, Alexanderson K, Pyle J, Zahm S, Wegman D, Stock SR, de Grosbois S (2003) Be the fairest of 
them all: challenges and recommendations for the treatment of gender in occupational health research. Am $\mathrm{J}$ Ind Med 43:618-629

Mohren DCL, Jansen NWH, van Amelsvoort LPGM, Kant IJ (2007) An epidemiological approach of fatigue and work. Experiences from the Maastricht Cohort Study. Programma Epidemiologie van Arbeid en Gezondheid Maastricht University, Maastricht

Mohren DCL, Jansen NWH, Kant IJ (2010) Need for recovery from work in relation to age: a prospective cohort study. Int Arch Occup Environ Health 83:553-561

Niedhammer I, Saurel-Cubizolles MJ, Piciotti M, Bonenfant S (2000) How is sex considered in recent epidemiological publications on occupational risks? Occup Environ Med 57:521-527

Remery C, Henkens K, Schippers J, Ekamper P (2003) Managing an aging workforce and a tight labor market: views held by Dutch employers. Popul Res Policy Rev 22:21-40

Salthouse TA (2006) Mental exercise and mental aging: evaluating the validity of the "Use It or Lose It" hypothesis. Perspect Psychol Sci 1:68-87

Silverstein BA, Fine LJ, Amstrong TJ (1986) Hand wrist cumulative trauma disorders in industry. Br J Ind Med 43:779-784

Sluiter JK, Frings-Dresen MHW, van der Beek AJ, Meijman TF (2001) The relation between work-induced neuroendocrine reactivity and recovery, subjective need for recovery, and health status. J Psychosom Res 50:29-37

Sluiter JK, de Croon EM, Meijman TF, Frings-Dresen MH (2003) Need for recovery from work related fatigue and its role in the development and prediction of subjective health complaints. Occup Environ Med 60:i62-i70

Statistics Netherlands (2011) Mannen en voltijders werken de meeste uren over [Men and full-timers most likely to work overtime]. http://www.cbs.nl/en-GB/menu/themas/arbeid-sociale-zekerheid/ publicaties/artikelen/archief/2011/2011-3521-wm.htm?Language switch $=$ on. Accessed 28 Nov 2013

Statistics Netherlands (2012a) Bevolkingprognose 2012-2060: langer leven, langer werken [Population prognosis 2012-2060: live longer, work longer]. http://www.cbs.nl/NR/rdonlyres/ DB34C87D-823D-49B4AE3AA3DE66CDCB1A/0/2012bevolki ngprognoselangerlevenlangerwerken.pdf. Accessed 10 June 2013

Statistics Netherlands (2012b) Emancipatiemonitor 2012 [Emancipation Monitor 2012]. http://www.cbs.nl/NR/rdonlyres/F5DF25651721-40A4-BF16-FF7852AAC53D/0/emancipatiemonitor2012. pdf. Accessed 28 Nov 2013
Statistics Netherlands (2013) Beroepsbevolking; kerncijfers naar geslacht en andere persoonskenmerken [Labour force; key figures by gender and other personal characteristics]. http://statline. cbs.nl/StatWeb/publication/?DM=SLNL\&PA=71958NED\&D1 $=311 \& \mathrm{D} 2=0 \& \mathrm{D} 3=0,710 \& \mathrm{D} 4=51,56 \& \mathrm{HDR}=\mathrm{G} 3, \mathrm{~T} \& \mathrm{STB}=\mathrm{G} 1$, $\mathrm{G} 2 \& \mathrm{VW}=\mathrm{T}$. Accessed 4 July 2013

Sterns HL, Alexander RA (1987) Industrial gerontology: the aging individual and work. Annu Rev Gerontol Geriatr 7:243-264

Van Amelsvoort LGPM, Kant IJ, Bültmann U, Swaen GMH (2003) Need for recovery after work and the subsequent risk of cardiovascular disease in a working population. Occup Environ Med 60:i83-i87

Van Dijk FJH, van Dormolen M, Kompier MA, Meijman TF (1990) Herwaardering model belasting-belastbaarheid [Re-evaluation of the model of work load and work capacity]. T Soc Gezondheidsz 68:3-10

Van Veldhoven M (2008) Need for recovery after work. An overview of construct, measurement and research. In: Houdmont J, Leka S (eds) Occupational health psychology: European perspectives on research, education and practice, 3rd edn. Nottingham University Press, Nottingham, pp 1-25

Van Veldhoven M, Broersen S (2003) Measurement quality and validity of the "need for recovery" scale. Occup Environ Med 60:i3-i9

Van Veldhoven M, Meijman TF (1994) Het meten van psychosociale arbeidsbelasting met een vragenlijst: de vragenlijst beleving en beoordeling van de arbeid (VBBA) [The measurement of psychosocial job demands with a questionnaire (VBBA)]. NIA, Amsterdam

Verdonk P, Hooftman WE, van Veldhoven MJPM, Boelens LRM, Koppes LLJ (2010) Work- related fatigue: the specific case of highly educated women in the Netherlands. Int Arch Occup Environ Health 83:309-321

Von Bonsdorff ME, Huuhtanen P, Tuomi K, Seitsamo J (2010) Predictors of employees' early retirement intentions: an 11-year longitudinal study. Occ Med 60:94-100

World Health Organization (1993) Aging and working capacity: report of a WHO study group. World Health Organization, Geneva

Wright JD, Hamilton RF (1978) Work satisfaction and age: some evidence for the 'job change' hypothesis. Soc Forces 56:1141-1158

Wu AD, Li Z, Zumbo BD (2007) Decoding the meaning of factorial invariance and updating the practice of multi-group confirmatory factor analysis: a demonstration with TIMSS Data. PARE $12: 1-26$ 